\title{
Viability Study of the Use of Cast Iron Open Cell Foam as Microbial Fuel Cell Electrodes**
}

\author{
By Carlo Mapelli, Valeria Mapelli, Lisbeth Olsson, Davide Mombelli, ${ }^{*}$ Andrea Gruttadauria \\ and Silvia Barella
}

Nowadays, the development of new green technologies has been promoted worldwide both by public and private institutions. In this context the research on microbial fuel cells (MFC) represents a promising alternative to carbon based energy sources. Unfortunately, this technology has been always affected by too low current density output for allowing an intensive application in the industrial and civil field. The study deals with this limitation and focuses on the implementation of metallic sponges, specifically cast iron based, as electrodes, aiming at increasing the exposed surface and thus the current density at the MFC anode. Cast iron was selected because of its low toxicity for the microorganisms, however its high melting point carries several problems for the manufacture process. Parallel to this, the realization of electrodes using foamed metals implies further issues related to the generation of correct pore size distribution and adequate bacterial activity. For instance, the metal foams are expected to be open-cell type, so that there can be an efficient mass transport also to the inner regions of the electrode. In order to control these parameters the metal sponges are produced by infiltration of cast iron on ceramic beds. Combining previous data with the measurements of power generation efficiency the authors conclude the study attempting to design MFCs with metal foamed electrodes.

The last decades witness a significant growth in public awareness towards environmental issues, resulting in an increasing demand of operative "green" solutions able to provide energy and chemicals without relying on the fossil-fuels. Therefore, the scientific research has been driven to face new challenges by both public administration and private sector. The present work plays along this line of action aiming at improving the performances of microbial fuel cell (MFC) systems.

A MFC is a bio-electrochemical system that converts chemical energy stored in chemical bonds of organic substrates directly into electricity. In this system bacteria are typically used as bio-catalysts thanks to their ability to oxidize organic substrates and transfer the liberated electrons to electron acceptors.

While soluble molecules (e.g., $\mathrm{O}_{2}, \mathrm{NO}_{3}^{-}, \mathrm{SO}_{4}^{2-}$ ) are typically used from most bacteria as electron acceptors, bacteria thriving in MFCs can live under anaerobic conditions and are typically

[*] Prof. C. Mapelli, D. Mombelli, Dr. A. Gruttadauria,

Dr. S. Barella

Dipartimento di Meccanica, Politecnico di Milano, Via La Masa 1, 20156 Milano, Italy

E-mail: davide.mombelli@mail.polimi.it

Prof. L. Olsson, Dr. V. Mapelli

Department of Chemical and Biological Engineering, Chalmers University of Technology, SE-412 96 Göteborg, Sweden

[**] The authors would like to thank Göteborg Energi Forskningsstiftelsen for financing this study. able to transfer electrons to external insoluble electron acceptors. Under anaerobic conditions in a MFC anode chamber, bacteria produce carbon dioxide, protons, and electrons via oxidation of organic substrates, as described by reaction (1) and transfer electrons to an external insoluble electron acceptors (i.e. the anode). The electrons then flow through an external resistor to a cathode, where the final electron acceptor (e.g., $\mathrm{O}_{2}$ ) is reduced and in this way electrical current is generated. ${ }^{[1,2]}$

$\mathrm{C}_{6} \mathrm{H}_{12} \mathrm{O}_{6}+6 \mathrm{H}_{2} \mathrm{O} \rightarrow 6 \mathrm{CO}_{2}+24 \mathrm{H}^{+}+24 \mathrm{e}^{-}$

Anode and cathode chambers are kept under anaerobic and aerobic conditions, respectively and are separated by a proton exchange membrane (PEM). A schematic representation of a typical two-chambers MFC is shown in Figure 1.

The mechanisms at the basis of electron transfer from the microbial cells to the anode are still under study, as the efficiency of the transfer is crucial in determining the efficiency of the MFC. ${ }^{[3]}$ Two main mechanisms of electron transfer to the anode can be distinguished:

(1) mediated electron transfer and

(2) direct electron transfer.

Both mechanisms require linking species that are capable to electronically link microbial cells to the electrode facilitating the electron transfer. ${ }^{[3]}$ In the first case the link is a soluble 


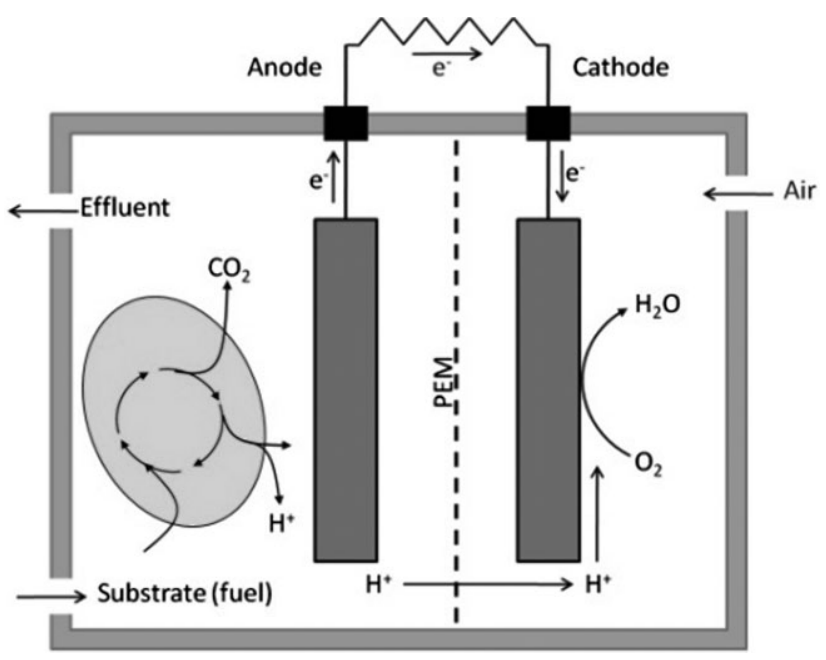

Fig. 1. Schematic representation of a MFC.

molecule, while direct electron transfer relies on membrane bound proteins and therefore on the direct contact between the microbial cell membrane and the anode, where the cells can form a so called biofilm.

Among the several factors influencing the efficiency of MFCs, both the anodic potential and the anodic surface are crucial. A critical anodic potential seems to exist at which a maximum power output of a microbial fuel cell is achieved. ${ }^{[4]}$ Furthermore, it has been shown that the density of the biofilm on the anode is also crucial and that it can be greatly influenced by the composition and the structure of the electrode. In particular, it is known that the biofilm density and the current density at the anode are proportional, therefore increasing the available surface for biofilm formation leads to higher current density. ${ }^{[5]}$

The present work intended to investigate a viable solution to increase the energy production efficiency of MFC devices by evaluating the effect of different anode structures. In particular, we increased the unit of available electrode surface for the formation of the biofilm by using open cell metallic foams iron-based alloys which, thanks to their low toxicity and good conductivity, represented the electrode material of choice. The specific material selected was cast iron, which features a lower melting point with a slightly higher conductivity than conventional steel. ${ }^{[5]}$ Nonetheless, the elevated melting temperature still represents a crucial challenge in the manufacture process.

The production method employed to realize these electrode-foams is based on the principle of infiltration of a molten metal into a ceramic space-holder patented in Politecnico di Milano by Prof. Carlo Mapelli and Prof. Enrique M. Castrodeza. ${ }^{[6]}$ Moreover, the space-holders employed consist in silicon carbide foundry filters selected for their high chemical and thermal stability. ${ }^{[7]}$
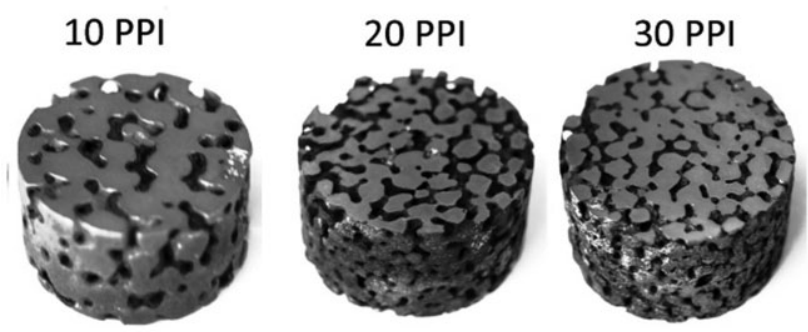

$\stackrel{20 \mathrm{~mm}}{ }$

Fig. 2. Cast iron foams featured by different porosities.

\section{Experimental}

\subsection{Sponge Production Route}

The melting process involved a rotating induction melting furnace in order to realize an efficient infiltration process of the liquid metal within the porosities of the ceramic frame. ${ }^{[8]}$ The entire heating apparatus is designed to rotate allowing shoving the liquid metal into the mould by centrifugal force. Once cooled down to room temperature, the sponges are supposed to be immerged in acid solution designed to etch exclusively the ceramic template. Specifically, the re-crystallized $\beta$-SiC space-holders were dissolved by wet chemical etching in an aqueous solution of HF ( $25 \mathrm{vol} \%)$. It is worth to mention that, the possibility of easily removing the ceramic template by etching in $\mathrm{HF}$ solution or molten $\mathrm{NaOH}$ is the main reason behind the choice of $\mathrm{SiC}$ as space-holder. The process successfully provided a series of cast iron open-cells foams of different porosity grade, that is, 10, 20, and 30 pores per inch (PPI; Figure 2). Indeed, provided an accurate and reliable space-holder setup, the process allows the operator to control and tailor the porosity, morphology and relative density of the foam by just employing the correct mould. A more detailed and specific description of the production procedure is reported in previous work by Prof. Mapelli. ${ }^{[8]}$

The sponges consisted of void channels surrounded by the metal. They are the negative print of the filter, showing an arbours morphology and presenting an open structure suitable for fluid transport, as shown in Figure 3.

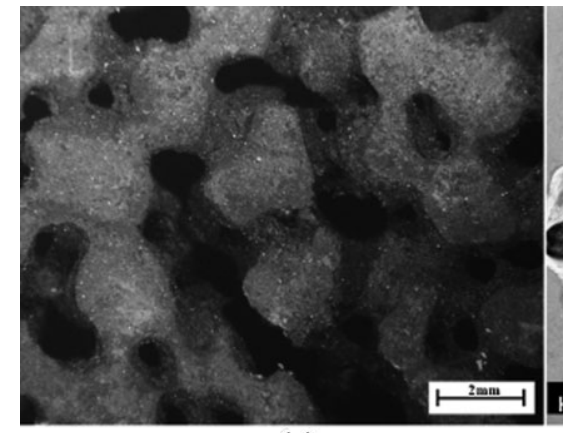

(a)

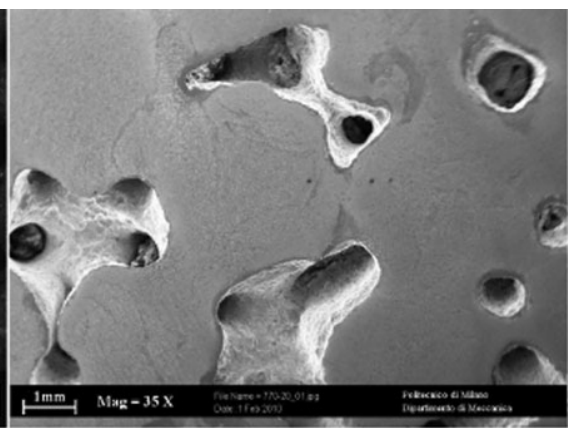

(b)

Fig. 3. SEM detailed view of cast iron sponges featured by a porosity equal to 20 PPI: (a) stereoscopic capture and (b) an example of a SEM-SE picture. 
Table 1. Morphological features of cast iron sponges (10 PPI) used as anode.

\begin{tabular}{lccc}
$\begin{array}{l}\text { Relative density } \\
{\left[\rho_{\mathrm{r}}\right]}\end{array}$ & $\begin{array}{c}\text { Porosity } \\
{\left[\varepsilon_{\mathrm{t}}\right]}\end{array}$ & $\begin{array}{c}\text { Surface to volume } \\
\text { ratio }\left[\mathrm{m}^{2} / \mathrm{m}^{3}\right]\end{array}$ & $\begin{array}{c}\text { Ligament size/ } \\
\text { void size }\end{array}$ \\
\hline 0.59 & 0.41 & 4.9 & 4.8
\end{tabular}

Table 2. Chemical composition of the cast iron struts.

\begin{tabular}{lcccccccc}
$\begin{array}{l}\text { Chemical } \\
\text { composition } \\
\text { [wt\%] }\end{array}$ & $\mathrm{C}$ & $\mathrm{Si}$ & $\mathrm{Mn}$ & $\mathrm{Cu}$ & $\mathrm{P}$ & $\mathrm{S}$ & $\mathrm{Mg}$ & $\mathrm{Al}$ \\
\hline GS800 & 3.5 & 2 & $<0.6$ & 0.6 & 0.05 & 0.02 & 0.07 & 0.008
\end{tabular}

The relative densities $\left(\rho_{\mathrm{r}}\right)$, the total porosity $\left(\varepsilon_{\mathrm{t}}\right)$, the surface to volume ratio and the ligament size to void size ratio were measured by geometrical calculations and by image analysis. ${ }^{[8]}$ These morphological parameters are reported in Table 1.

The chemical composition of the metallic struts, provided by X-ray diffraction analysis, is reported in Table 2. The results showed that there was no alteration in the chemical composition of the metal due to the interaction with $\mathrm{SiC}$, $\mathrm{HF}$, or with the external atmosphere during the sponges processing. The chemical composition corresponded to the standard requirement for spheroidal cast Iron GS-800 grade (UNI EN 1563).

For micro-structural analysis, the samples were polished and etched in a chemical solution (Nital 2\%) to reveal grain boundaries. Optical microscopy observation pointed out that the as-cast specimens (Figure 4) yielded a solidification structure which features dendrites, according to the microstructure available in the literature for this alloy. ${ }^{[9,10]}$

The sponges were further machined in a dedicated electrode shape by high-precision micro-cutter and then laser welded to assure the final correct dimensions and to provide material and electrical continuity (Figure 5).

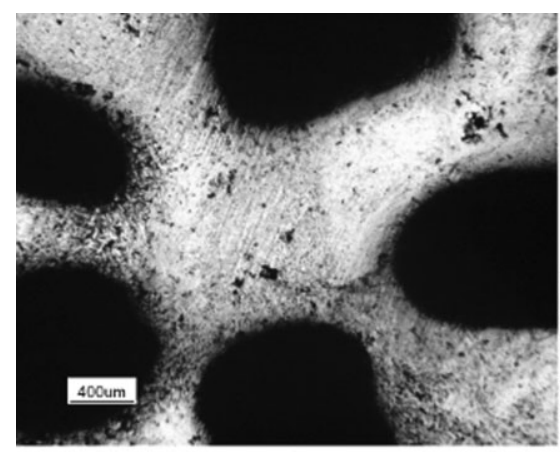

(a)

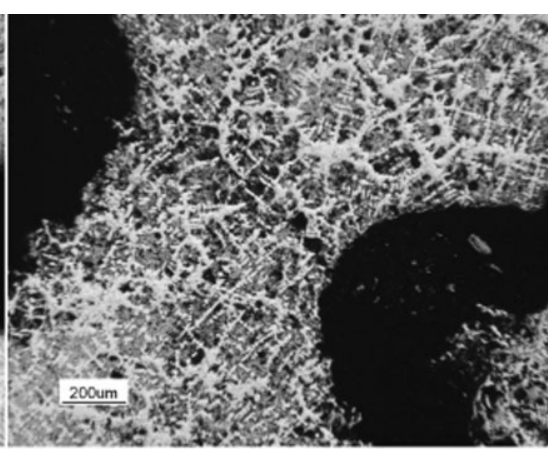

(b)
Fig. 4. Microstructural investigation of processed cast iron sponge at different magnifications (a) before and (b) after etching in Nital $2 \%$.

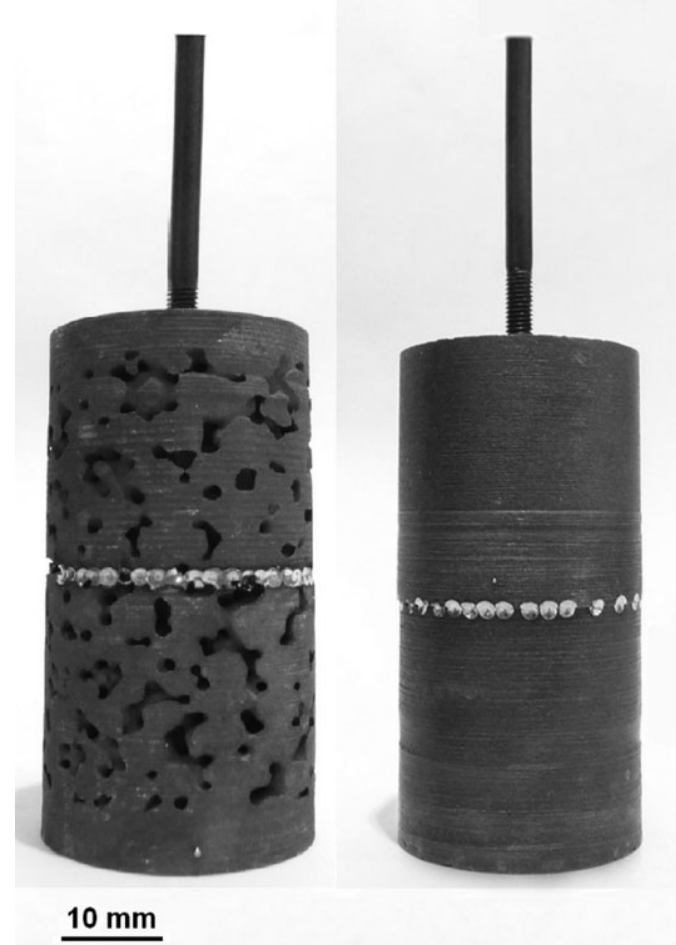

Fig. 5. MFC electrodes: on the left the foamed ones (10 PPI) and the massive on the right.

\subsection{Media and Microorganisms}

The anode chamber containing $250 \mathrm{ml}$ of buffered growth medium $\left(9 \times 10^{-3} \mathrm{M} \quad\left(\mathrm{NH}_{4}\right)_{2} \mathrm{SO}_{4}, \quad 5.7 \times 10^{-3} \mathrm{M} \quad \mathrm{K}_{2} \mathrm{HPO}_{4}\right.$, $3.3 \times 10^{-3} \mathrm{M} \quad \mathrm{KH}_{2} \mathrm{PO}_{4}, \quad 2 \times 10^{-3} \mathrm{M} \quad \mathrm{NaHCO}_{3}, \quad 1.01 \times 10^{-3} \mathrm{M}$ $\mathrm{MgSO}_{4}, \quad 0.485 \times 10^{-3} \mathrm{M} \quad \mathrm{CaCl}_{2}, \quad 67.2 \times 10^{-6} \mathrm{M} \quad \mathrm{Na}_{2}$ EDTA, $56.6 \times 10^{-6} \mathrm{M} \mathrm{H}_{3} \mathrm{BO}_{3}, 125 \times 10^{-3} \mathrm{M} \mathrm{NaCl}, 5 \times 10^{-3} \mathrm{M}$ HEPES, $0.5 \mathrm{~g} \cdot 1^{-1}$ yeast extract, $0.5 \mathrm{~g} \cdot \mathrm{1}^{-1}$ tryptone, $5.4 \times 10^{-6} \mathrm{M} \mathrm{FeSO}_{4}$, $5 \times 10^{-6} \mathrm{M} \mathrm{CoSO}_{4}, 5 \times 10^{-6} \mathrm{M} \mathrm{Ni}\left(\mathrm{NH}_{4}\right)_{2}\left(\mathrm{SO}_{4}\right)_{2}, 3.87 \times 10^{-6} \mathrm{M}$ $\mathrm{Na}_{2} \mathrm{MoO}_{4}, \quad 1.5 \times 10^{-6} \mathrm{M}_{2} \quad \mathrm{Na}_{2} \mathrm{SeO}_{4}, 1.26 \times 10^{-6} \mathrm{M}_{4} \mathrm{MnSO}_{4}$, $1.04 \times 10^{-6} \mathrm{M} \mathrm{ZnSO}_{4}, 0.2 \times 10^{-6} \mathrm{M} \mathrm{CuSO}_{4}{ }^{[11,12]}$ supplemented with $20 \times 10^{-3} \mathrm{M}$ Na-L-lactate was inoculated with Shewanella oneidensis MR1. ${ }^{[13]}$ The same medium without supplementation of Na-L-lactate was used for the cathode chamber. The head space of the anode chamber was continuously flushed with sterile $\mathrm{N}_{2}$ in order to keep anaerobic conditions, while the medium in the cathode chamber was continuously flushed with air in order to provide oxygen as final electron acceptor.

In Figure $6 \mathrm{~b}$ a particular of a porosity filled by the organic matter containing the bacteria is shown.

\subsection{MFC Configuration}

Structure of MFC was a typical 2-chambers structure constructed with $250 \mathrm{ml}$ standard borosilicate media bottles (Figure 7), and fitted with GL14 glass threaded ports (Adams \& Chittenden Scientific Glass, Berkeley, USA). 


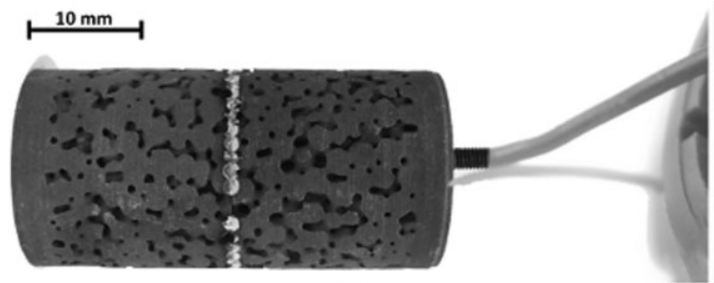

(a)

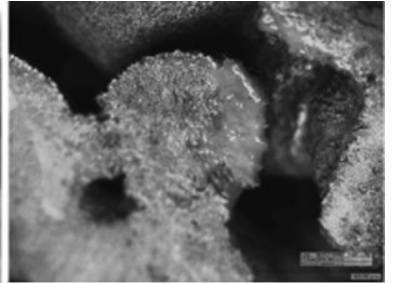

(b)

Fig. 6. (a) Particular of sponge anode electrical connection and (b) particular of a foam porosity filled by bacteria.

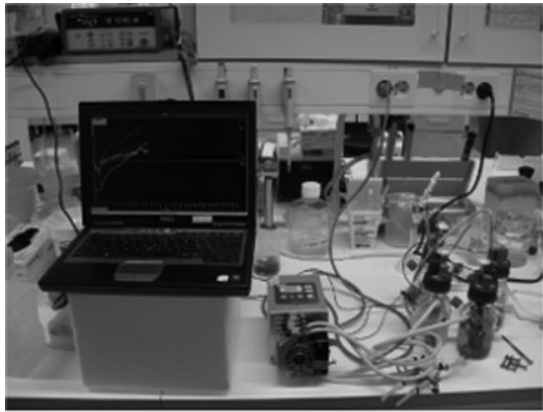

(a)

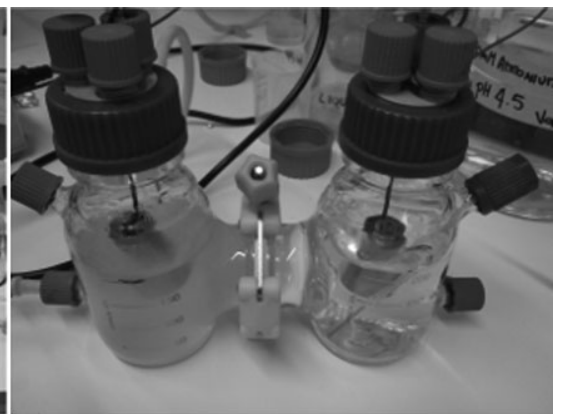

(b)

Fig. 7. Experimental employed MFC apparatus (a) and particular of the two chambers (b).

The two chambers were connected using glass flanges with $40 \mathrm{~mm}$ diameter and separated with a proton exchange membrane (PEM) made of Nafion ${ }^{\mathbb{R}}$ NR-212. Nafion ${ }^{\mathbb{R}}$ membranes were treated before use as described. ${ }^{[14]}$ In particular, they were boiled for two hours in $3 \% \mathrm{H}_{2} \mathrm{O}_{2}$, boiled for $1 \mathrm{~h}$ in milliQ water, boiled for $2 \mathrm{~h}$ in $0.5 \mathrm{M} \mathrm{H}_{2} \mathrm{SO}_{4}$ and in $\mathrm{mQ}$ water for $1 \mathrm{~h}$. Membranes were stored in $\mathrm{mQ}$ water until used. Electric wires (ELFA AB, Järfälla, Sweden) were copper wires with $0.25 \mathrm{~mm}^{2}$ conductive area and $0.19 \mathrm{~mm}$ diameter including the insulating sheathing made of silicon and resistant to -50 to $+180^{\circ} \mathrm{C}$. Both anode and cathode were made of cast iron under massive (control) or sponge structure (selecting as first attempt the foam electrode featured by 10 PPI of porosity). Every batch was run for at least $120 \mathrm{~h}$. Results are from two independent experimental replicates. Measurements of the power output were obtained by using an Agilent HP 34972A data acquisition/switch unit (Agilent Technologies, USA). Every $15 \mathrm{~min}$, a full channel scan was performed for measurement of electric potential $(V)$ in Volts and current $(I)$ in Amperés. The data acquisition unit was controlled and monitored via Agilent BenchLink Data Logger Pro software (Agilent technologies, USA) and the data stored. The maximum external system resistance $(R)$ ranged from $120-480 \Omega$.

\section{Results and Discussion}

Two-chamber MFC systems with external resistor of $480 \Omega$ were run using cast iron electrodes regularly monitoring voltage and current output for at least $120 \mathrm{~h}$. Voltage and current outputs of MFC systems with foam structured electrodes (10 PPI) were compared with outputs of MFC carrying massive electrodes (Figure 8). While the voltage output in the massive system was never completely stable, voltage in MFC with foam electrodes reached stability within about $48 \mathrm{~h}$. The difference between the massive electrode and the foamed ones, might be related to a faster and more stable biofilm formation on the foamed anode, compared to the massive one. The voltage output of the foamed systems reached a maximum of about $103 \mathrm{mV}$ in the first run and $85 \mathrm{mV}$ in the second run using the 10 PPI system. Further increase of voltage output was noticed after a pulse addition of lactate in the foamed systems. The differences observed between the foamed systems and the massive one might be related to a higher surface to volume ratio in the $10 \mathrm{PPI}$ anode, compared to the massive one. In fact, the bacterial colonization of the electrode surface is extended to a wider surface, thus allowing a more efficient electron transfer to the anode.

Although the output values achieved were rather low, they are comparable with typical outputs of MFC systems and, most importantly, a clear advantage was brought by the use of foam electrodes compared to the massive ones. Furthermore, the use of mixed bacterial populations (here we used a pure population of S. oneidensis) would result in a more efficient system. Therefore, it is worth testing metal foam electrodes in bioelectrochemical systems driven by mixed bacterial consortia, which would also be better representative of actual systems that can be installed for treatment of waste streams.

After conducting MFC experiments, electrodes showed general and extended corrosion by organic material (Figure 9).

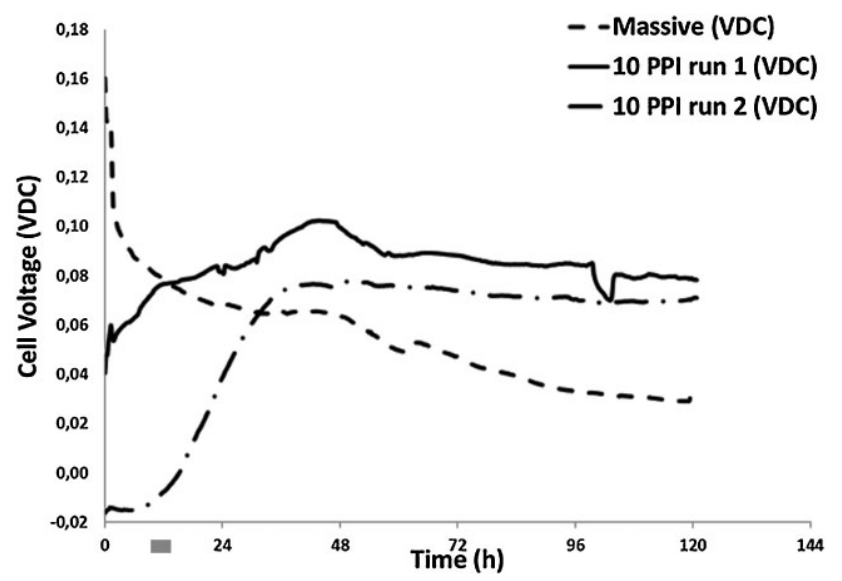

Fig. 8. MFC performance over 120 h of batch operation using $S$. oneidensis growing on $20 \times 10^{-3}$ M lactate as carbon source and electrodes made of massive (dashed line) or foam (continuous and dash-dotted line) cast iron. 


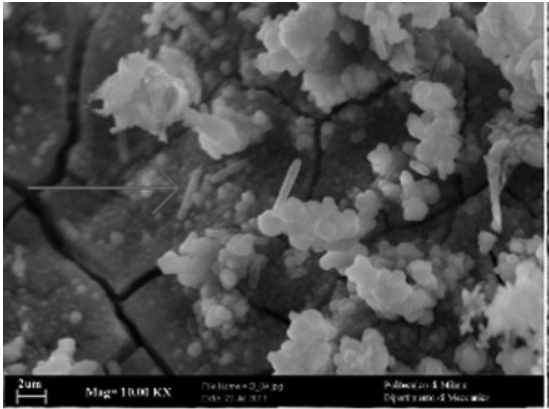

(a)

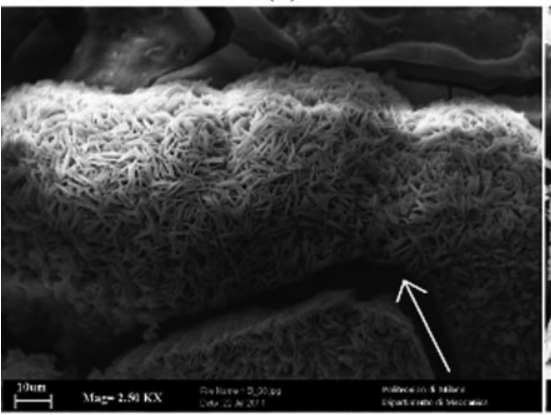

(c)

Fig. 9. SEM macrographs of foamed electrode after experiments: (a) particular of dead bacteria; (b-d) different oxide layer morphologies formed on electrode surfaces.

Thorough scanning electron microscopy (SEM) analysis, coupled with X-ray emission spectrometry (EDS) probe, it was possible to identify residuals of dead bacteria (grey arrow in Figure 9a) and the morphology and composition of oxide layers, mainly constituted by Fe and P oxide (white arrow in Figure 9b-d).

Table 3 reports the chemical composition of the oxides found on the anode surface after running the test. The chemical composition of the oxides was similar for their different morphologies. In particular, the oxide reported in Figure 9a shows a globular shape, whereas the others are characterized by an arborous growth. In particular, the arborous oxides are found in the pores while the globular one is found on the surface. This was probably due to the different chemical composition of the fluids and the stagnation of organic matter used for the bacteria metabolism. Moreover, the pore regions are attracted by a magnetic field (provided by electricity circulation) that clouts the oxides growth, giving preferential growth directions, and consequently leading to the presence of different branches.

The loss of power found at the end of the test is due to the exceeding oxidation that compromises the electrical conductivity of the sponge electrodes.

\section{Conclusions}

In this work, we demonstrated that the foam structure of electrodes made of metal alloys can improve the performance of MFC. Although this improvement given by the foam structure was detectable even with cast iron electrodes, corrosion phenomena occurring on this kind of material could impair the performance of bioelectrical systems. Therefore it is worth testing foam-structured alloys that are less prone to corrosion in order to by-pass the corrosion drawbacks while maintaining the advantages of the foamstructure. ${ }^{[15]}$

It is also important to mention that MFCs have several limitations that will never make them a competitive technology for electrical energy production; however, bio-electrochemical systems are a promising technology if coupled to other existing processes, such as waste water treatment, as they can improve the process and also recover part of the costs of waste water treatment plants.

The experimental work proved the cellular structure of the employed electrodes yields noteworthy improvements in both stability and efficiency of the MFC system, while the overall system structure can be improved in order to facilitate mass transfer through the anode.

The positive results of using foams as electrode suggest interesting future developments of MFC-foam system along two research line: developing foams based on non-toxic high corrosion resistant material and investigating the effect of different $\mathrm{S} / \mathrm{V}$ ratios on the electrical performances of microbial cell.

Received: April 14, 2012 Final Version: July 18, 2012

[1] K. Rabaey, W. Verstraete, Trends Biotechnol. 2005, 23, 291.

[2] H. P. Bennetto, Biotechnol. Educ. 1990, 1, 163.

[3] U. Schroder, Phys. Chem. Chem. Phys. 2007, 9, 2619.

[4] Ky. Cheng, G. Ho, R. Cord-Ruwisch, Environ. Sci. Technol. 2008, 42, 3828.

Table 3. Chemical composition of anode oxide layer and organic residual of bacteria activity.

\begin{tabular}{|c|c|c|c|c|c|c|c|c|c|c|c|}
\hline Spectrum [wt $\%]$ & $\mathrm{C}$ & $\mathrm{O}$ & $\mathrm{Na}$ & $\mathrm{Mg}$ & $\mathrm{Si}$ & $\mathrm{P}$ & $\mathrm{Cl}$ & K & $\mathrm{Ca}$ & $\mathrm{Fe}$ & $\mathrm{Cu}$ \\
\hline $\mathrm{a}$ & 11.97 & 50.91 & 1.40 & 1.35 & 0.07 & 11.55 & 0.33 & 1.60 & 0.99 & 19.83 & \\
\hline$b$ & 7.22 & 30.01 & 0.58 & 0.74 & 1.29 & 5.93 & 3.66 & 0.61 & 0.55 & 48.23 & 1.17 \\
\hline c & 9.68 & 40.54 & 0.84 & 1.09 & 0.20 & 11.52 & 0.22 & 0.87 & 0.64 & 32.90 & 0.46 \\
\hline $\mathrm{d}$ & 4.69 & 27.72 & 0.87 & & 0.37 & 18.45 & & 1.74 & 0.42 & 46.12 & \\
\hline
\end{tabular}


[5] B. Logan, in Microbial Fuel Cells, John Wiley \& Sons, Inc., Hoboken, New Jersey 2008.

[6] E. M. Castrodeza, C. Mapelli, Metal foams by molten metal infiltration of a ceramic particles bed, Italian Industrial Patent Process MO 2008 A 166, 2008.

[7] V. Villavecchia, G. Eigenmann, Nuovo dizionario di merceologia e chimica applicata, Vol. 6, Hoepli, Milano, Italy 1996.

[8] E. M. Castrodeza, A. Gruttadauria, C. Mapelli, D. Mombelli, Steel Res. Int. 2011, 82, 918.

[9] W. Nicodemi, in: Acciai e leghe non ferrose, Zanichelli, Bologna, Italy 2000.

[10] ASM Handbook, in: Metallography and Microstructures, Vol. 9, ASM International, Materials Park (OH) 2004.

[11] C. R. Myers, K. H. Nealson, Science 1988, 240, 1319.
[12] M. A. Rosenbaum, H. Y. Bar, Q. K. Beg, D. Segre, J. Booth, M. A. Cotta, L. T. Angenent, Bioresour. Technol. 2011, 102, 2623.

[13] K. Venkateswaran, D. P. Moser, M. E. Dollhopf, D. P. Lies, D. A. Saffarini, B. J. MacGregor, D. B. Ringelberg, D. C. White, M. Nishijima, H. Sano, J. Burghardt, E. Stackebrandt, K. H. Nealson, Int. J. Syst. Bacteriol. 1999, 49, 705.

[14] F. Aulenta, P. Reale, A. Canosa, S. Rossetti, S. Panero, M. Majone, Biosens. Bioelectron. 2010, 25, 1796.

[15] C. Mapelli, A. Gruttadauria, D. Mombelli, S. Barella, E. M. Castrodeza, Proc. of 7th European Stainless Steel Conference, paper 122, 21-23 September 2011, Como, Italy. 